\title{
PERSONALIDADE ORGANIZACIONAL - UMA VISÃO HUMANIZADA \\ DAS ORGANIZAÇÕES
}

\section{ORGANIZATIONAL PERSONALITY - A VISION OF HUMANIZED ORGANIZATIONS}

Data do recebimento do artigo: 4/01/2014

Data do aceite do artigo: $24 / 3 / 2014$

Data da publicação: 23/06/2014

Processo de Avaliação: Double Blind Review

Francisca Candida Candeias de Moraes ${ }^{1}$

Mestre em Gestão Empresarial

Fundação Getulio Vargas

Heloisa Candia Hollnagel

Doutora em Ciências Biológicas - Universidade de São Paulo

Professora da Universidade Federal de São Paulo

\section{RESUMO}

As instituições se assemelham às pessoas em diversos aspectos e o presente estudo, de natureza exploratória e metodologia de base teórica e empírica, visa identificar os elementos comuns na construção e desenvolvimento da personalidade individual e institucional, concentrada nos modos de "ser", "pensar" e "agir". Os resultados preliminares apontam para similaridades, em especial no tema do "herói", foco na continuidade deste trabalho.

Palavras chave: Gestão do Conhecimento; Vantagem Competitiva; Cultura Organizacional.

\begin{abstract}
Institutions are similar to individuals in many aspects and the present study, exploratory in nature and using methodology of theoretical and empirical basis, aims to identify common elements in the construction and development of individual and institutional personality, focused on ways of "being", "thinking" and " acting". Preliminary results point to similarities, especially on the theme of "hero", target on further work.
\end{abstract}

Keywords: Knowledge Management; Competitive Advantage; Organizational Culture.

\footnotetext{
${ }^{1}$ Autor para correspondência: Universidade de Taubaté - Av. Nove de Julho, 2029, Bela Vista, São Paulo, SP, Brasil. CEP 01313-902.
} 


\section{INTRODUÇÃO}

Muito se tem escrito sobre os aspectos que devem ser priorizados pelos consultores na análise de empresas, principalmente no desenvolvimento de trabalhos voltados à (re)estruturação organizacional. No entanto, a maioria das metodologias pauta-se em características pressupostamente passiveis de alteração no ambiente visível (interno e externo) da instituição, desprezando aspectos intrínsecos, inerentes ao escopo das relações humanas. São observáveis, nas organizações, aspectos surgidos quando da constituição da mesma ou desenvolvidos ao longo de sua história, que permaneceram atuantes ao longo do tempo, mesmo que invisíveis ou subliminares, nem sempre considerados nas atividades de gestão ou consultoria.

Esse é o foco deste trabalho, de cunho exploratório, desenvolvido a partir de referências bibliográficas e de observações empíricas em atividades de consultoria; ainda não tendo sido explorado em pesquisa científica, tem como objetivo principal identificar as características que, a princípio, comporiam a "personalidade institucional", conceituando-se, para fins de entendimento, personalidade como "um 'constructo primário' que inclui pensamentos, motivos, emoções, interesses, atitudes, capacidades e fenômenos semelhantes" (DAVIDOFF, 1983).

Considerando que as instituições são constituídas por pessoas que, apesar das características individuais distintas, no ambiente organizacional trocam conhecimentos e experiências e comungam visões que afetam o ambiente no qual estão inseridas e são afetadas pelas relações com os demais e com a cultura reinante - princípios, valores, crenças e atitudes.

Investigações iniciais na biologia sobre o comportamento animal (etologia) em grupos estáveis mostraram padrões fixos de ação [fixed action patterns]. Estas estruturas comportamentais foram consideradas inatas e produtos da seleção filogenética de adaptação coletiva (Lorenz, 1965). Entretanto, outros autores concluem que as dinâmicas da adaptação social refletem a interação contínua entre processos comportamentais e processos ecológicos (ou seja, o papel que desempenha) de uma dada espécie no seu habitat particular (CROOK, 1966; KUMMER, 1968).

É observado no ambiente organizacional que essa transferência mútua de informações gera alterações no ambiente institucional, que, consequentemente, permite ao indivíduo conhecer outras formas de ser e pensar e interfere nas características individuais internas e naquelas demonstráveis externamente; simultaneamente, parte do "novo pensar e agir" passam a ser parte da "personalidade" e da "vida" da organização de acordo com a rede de influência do(s) indivíduo(s), formando um ciclo contínuo de alterações. Assim, podemos resgatar o mito citado por Enriquez (1997):

a organização não pode viver sem segregar um ou alguns mitos unificadores, sem instituir ritos de iniciação, de passagem e de execução, sem formar os seus heróis tutelares (colhidos com freqüência entre os fundadores reais ou os fundadores imaginários da organização), sem narrar ou inventar uma saga que viverá na memória coletiva: mitos, ritos, heróis, que têm por função sedimentar a ação dos membros da organização, de lhes servir de sistema de 
legitimação e de dar assim uma significação preestabelecida às suas práticas e à sua vida. (ENRIQUEZ, 1997, p. 34).

Conceitualmente, personalidade contemporaneamente é definida como "padrões relativamente constantes e duradouros de perceber, pensar, sentir e comportar-se, os quais parecem dar às pessoas identidades separadas" (DAVIDOFF, 1983) ou, ainda, "conjunto de características que diferenciam uma pessoa de outra (modo de ser, de agir, de pensar)" (BIDDERMAN, 1998, p. 715)

Por outro lado, ao longo desta pesquisa nos deparamos com visões distintas de autores sobre o tema quando aplicado a organizações; enquanto alguns destacam a dificuldade na separação entre "pessoas" e "organizações", já que "não existem fronteiras muito definidas entre o que é e o que não é uma organização, bem como não se pode exatamente traçar os limites de influência de cada pessoa em uma organização" (CHIAVENATTO, 1985), outros reforçam a relação simbiótica existente no mundo organizacional, como ressalta FOSSÁ (2004):

\begin{abstract}
Nesse propósito, a organização vive do que quer ser e, por sua vez, o trabalhador também busca aquilo que pretende igualmente ser. Tanto a organização quanto o empregado vivem a imagem criada do modelo ideal. A organização busca a sagração do seu poder, a sua respeitabilidade, a sua importância social, política, econômica e financeira como garantia de sua continuidade e perpetuidade. Por sua vez, o empregado busca status, reconhecimento social e afetivo e busca, principalmente, a sua imortalidade nos produtos que fabrica, nos programas em que se envolve e na perspectiva de um futuro triunfante capaz de justificar todos os sacrifícios, todos os medos, todas as ameaças, todas as adversidades, todo o sofrimento físico e psíquico. (FOSSÁ, 2004, p. 11).
\end{abstract}

A partir desses conceitos e da experiência prática das autoras em consultoria em instituições públicas e privadas, com e sem fins lucrativos, foi proposto o desafio de identificar quais as características que poderiam compor a personalidade das organizações, ou seja, buscar respostas para a questão: "o que compõe o conjunto de características que as diferenciam umas das outras?".

Quais seriam essas características? Optamos por analisar a pressuposta "personalidade organizacional" a partir do conceito definido no verbete citado anteriormente. Para isso, "modo de ser" está sendo enfocado como o comportamento primário das instituições, a partir das relações internas entre os indivíduos e entre a organização e os indivíduos; o "modo de agir" como a forma com que ela interage com as demais instituições e com o ambiente externo e para "modo de pensar" a escolha recaiu sobre a escolha da(s) área(s) de atuação da empresa ao longo do tempo, sua estratégia básica em relação à visão da organização em relação ao seu papel na sociedade e na sua estratégia de convencimento dos stakeholders.

Metodologicamente, adotou-se pesquisa qualitativa fenomenológica, a partir do relato de experiências, e a revisão bibliográfica, realizada em periódicos da área de gestão nas bases 
de dados: Scopus, Web of Science, Ebsco e Scielo. A escolha das informações para essa reflexão esteve vinculada à necessidade de compreender o referencial simbólico, os códigos e as práticas deste universo específico. De acordo com Boemer (1994, p. 86) nesse tipo de abordagem, “... é preciso um interesse verdadeiro, autêntico, em desvelar o fenômeno, descobrir significados, desenvolver compreensão e explorar o fenômeno na maior diversidade possível”.

\section{CONCEITOS BÁSICOS}

\subsection{PERSONALIDADE}

Em obra que trata do comportamento organizacional, Robbins (2005, p. 78) aborda o conceito de personalidade como um elemento fluido e complexo que sofre alterações ao longo do tempo, perceptível através dos traços demonstrados pelo indivíduo, que reflete seu crescimento e desenvolvimento psicológico.

\footnotetext{
é a organização dinâmica interna daqueles sistemas psicológicos do indivíduo que determinam seu ajuste específico ao ambiente. A personalidade como a soma total das maneiras como uma pessoa reage e interage com as demais. Ela é mais freqüentemente descrita em termos dos traços mensuráveis exibidos por um indivíduo. (ROBBINS, 2005, p. 78)
}

De acordo com Freitas (1999, p. 91), a formação da personalidade decorre de variações contínuas de amor e ódio, decorrentes de constantes identificações, por vezes conflitantes entre si; no "modelo Big Five, a personalidade é definido como decorrente de um constructo, desenvolvido ao longo da vida humana: uma rede hierárquica de traços, compreendidos teoricamente como predisposições comportamentais de respostas às situações da vida" (TRENTINI et al., 2009). Esse modelo, um dos mais utilizados para identificar os traços de personalidade, analisa os seguintes traços, que pressupostamente justificam as diferenças entre as pessoas, de acordo com o grau entre as duas polaridades (indicadas entre parênteses) (DIGMAN, 1996), que também pode ser aplicados à análise organizacional:

- Extroversão (Introversão - Extroversão) - caracteriza os relacionamentos interpessoais;

- Neuroticismo (Estabilidade e Neuroticismo) - relacionadas à natureza do afeto, positivo ou negativo, à ansiedade e à estabilidade emocional;

- Conscienciosidade (Inescrupulosidade - Conscienciosidade) - caracterizado pelo grau de responsabilidade e honestidade, em um extremo, ou de negligência, irresponsabilidade, no outro; 
- Abertura para Experiência (Convencionalidade - Abertura) - enfoca a flexibilidade, criatividade e imaginação, abertura para novas experiências e curiosidade.

- Socialização (Anti-sociabilidade - Sociabilidade) - indica o grau de tendência à docilidade social e agradabilidade.

A percepção é definida por (ROBBINS, 2005, p. 104) como o "processo pelo qual os indivíduos organizam e interpretam suas impressões sensoriais com a finalidade de dar sentido ao seu ambiente", que pode ser completamente diferente da realidade existente. Assim, pode-se considerar que a percepção está condicionada ao grau de desenvolvimento em cada um dos fatores identificados no Modelo Big five.

\subsection{CULTURA ORGANIZACIONAL}

Estudos mostram que qualquer tipo de grupo social pode desenvolver uma determinada cultura: nacional, regional, familiar, comunitária, religiosa, profissional, setorial e organizacional, dentre outras (RUBEN, 2009).

Capra (2007, p. 83) conceitua padrão de organização de um sistema vivo como a "configuração das relações entre os componentes do sistema, configuração essa que determina as características essenciais do sistema; a 'estrutura' do sistema como a incorporação material desse padrão de organização; e o 'processo vital' como o processo contínuo dessa incorporação".

Segundo outras visões, as organizações consistem em um sistema composto pelos fatores cultural, simbólico e imaginário, entrelaçados, que podem ser analisados em sete aspectos: mítico, sócio-histórico, institucional, organizacional (stricto sensu), grupal, individual e pulsional (ENRIQUEZ, 1992).

ROBBINS (2005, p. 375) conceitua cultura organizacional como um "sistema de valores compartilhado pelos membros que diferencia uma organização das demais". Já outro autor, apresenta uma abordagem mais detalhada:

Entendo a cultura organizacional primeiro como instrumento de poder; segundo, como conjunto de representações imaginárias sociais que se constróem e reconstroem nas relações cotidianas dentro da organização e que se expressam em termos de valores, normas, significados e interpretações, visando um sentido de direção e unidade, tornando a organização fonte de identidade e de reconhecimento para seus membros.(FREITAS, 1999, p. 97)

Os valores são definidos por Robbins (2005, p. 54) como "as convicções básicas de que um modo específico de conduta ou de condição de existência é individualmente ou socialmente preferível a modo contrário ou oposto de conduta ou de condição de existência". 
Segundo Trice e Beyer (1993), as principais categorias de formas culturais são os símbolos, a linguagem, as narrativas e as práticas, sendo um mecanismo perceptivo de transmissão e reforço da cultura, que se manifestam nas seguintes formas:

\begin{tabular}{cl}
\hline Forma & \multicolumn{1}{c}{ Definição } \\
\hline Artefato & $\begin{array}{l}\text { Objetos materiais fabricados pelas pessoas para facilitar o desempenho de atividades de expressão } \\
\text { cultural. }\end{array}$ \\
\hline Cenário & $\begin{array}{l}\text { Objetos e coisas que circundam as pessoas,proporcionando estímulo sensoriais imediatos, } \\
\text { enquanto desempenham atividades culturalmente expressivas. }\end{array}$ \\
\hline $\begin{array}{c}\text { Conto } \\
\text { Popular }\end{array}$ & Narrativa completamente ficcional \\
\hline Estória & Narrativa que mistura verdade e ficção \\
\hline Gesto & Movimentos de partes do corpo para expressar significados \\
\hline Lenda & $\begin{array}{l}\text { Narrativa de evento maravilhoso, fundamentada em dados históricos, mas ressaltada com } \\
\text { elementos de ficção }\end{array}$ \\
\hline Linguagem & Sons e sinais escritos utilizados para a transmissão de significados entre membros de um grupo. \\
\hline Mito & $\begin{array}{l}\text { Narrativa dramática de eventos imaginados usada para explicar as origens ou a transformação de } \\
\text { algo. Pode ser também uma crença inquestionável em relação aos benefícios práticos de certas } \\
\text { técnicas e comportamentos e que não é sustentada por fatos. }\end{array}$ \\
\hline Ritual & $\begin{array}{l}\text { Técnicas e comportamentos padronizados e detalhados que gerenciam a ansiedade do grupo, mas } \\
\text { que raramente produzem as conseqüências técnicas práticas pretendidas. }\end{array}$ \\
\hline Saga & $\begin{array}{l}\text { Uma narrativa histórica e heróica que descreve a trajetória sem precedentes de um grupo e seus } \\
\text { líderes }\end{array}$ \\
\hline Símbolo & Significado expresso através de objeto, ato, evento, qualidade ou relação \\
\hline Quadro 1 - Manifestações da Cultura Organizacional, constructos de formas culturais. \\
Fonte: TRICE \& BEYER (1984)
\end{tabular}

Do ponto de vista simbólico, os mitos se destacam, na medida em que se apresentam como elementos balizadores dos valores institucionais, sendo transferidos de indivíduo a indivíduo como forma de reforçar o comportamento esperado de seus membros: "o mito é, ao mesmo tempo, uma estória contada e um esquema lógico que o homem cria para para resolver problemas que se apresentam sob planos diferentes, integrando-os numa construção sistemática" (LÉVI-STRAUSS, 1989).

Para Freitas (2002), a semelhança da figura do pai protetor, os heróis se constituem na forma pela qual as organizações "tornam o sucesso crível e atingível", criando uma dimensão simbólica que contribui para a reprodução de papéis, comportamentos e atitudes que influencia a (re)socialização do seu membro.

O herói aparentemente é uma das formas de explicar a teoria da primatologia, segundo a qual as relações sociais estão constantemente oscilando entre forças coesivas e dispersivas (CARPENTER, 1942; YERKES, 1928; ZUCKERMAN, 1932), diminuindo a dispersão social decorrente da competição (VERISSIMO, 2008). 


\subsection{INDÍCIOS DA “PERSONALIDADE” DAS ORGANIZAÇÕES}

\section{a) Modo de Ser}

De acordo com Robbins (2008), uma cultura organizacional pode surgir de três formas: no primeiro caso, os fundadores só contratam e mantêm funcionários que pensem e sintam as coisas da mesma forma que eles, no segundo doutrinam e socializam esses funcionários recém-contratados de acordo com sua forma de pensar e de sentir, ou ainda, por meio de um modelo a ser seguido pelos membros da organização, onde os funcionários são direcionados a se identificarem com os fundadores, introjetando seus valores, convicções e premissas.

A exemplo de qualquer ser humano, as instituições iniciam-se a partir de uma "família", sendo, desta forma, também sujeita às influências "genéticas" e de convívio social. Observa-se que as organizações carregam intrinsecamente as características básicas de seus "pais-fundadores", surgidas da ideia de uma pessoa, de um grupo de indivíduos ou da opção por uma determinada direção/meta central ("dom natural”).

No entanto, ao longo do tempo e da construção das relações, adquire características próprias, na medida em que "quando uma organização se institucionaliza, ela assume uma vida própria, independente de seus fundadores ou de qualquer de seus membros [...] passa a ter valor por si mesma, independente dos bens ou serviços que produz" (ROBBINS, 2005, p. 374).

Robbins (2005, p. 381) enfoca o processo de criação de uma cultura de três formas:

- Os fundadores contratam e mantêm pessoas que comungam suas ideias;

- Os colaboradores são doutrinados e socializados de acordo com a forma de pensar e sentir que os fundadores;

- a atuação dos fundadores atua como modelo a ser copiado pelos colaboradores, assim como seus valores, convicções e premissas.

Podemos citar como exemplo, a Microsoft, que incorpora, em sua filosofia de trabalho, o despojamento de Bill Gates. É evidente que o ambiente no qual a instituição está inserida provoca modificações internas dedicadas à adaptação, da mesma maneira que cada um de nós incorporou características de amigos na infância e juventude para obtermos a aceitação do grupo social não familiar, mas, na base de cada um de nós permanecem os valores básicos que aprendemos na infância e incorporamos como válidos, modificados apenas quando ocorre algum fato que abale nossas estruturas internas (casamento, nascimento de filho, perigo de vida, etc). Da mesma maneira, a instituição passa por modificações significativas ao longo de sua "vida", mas, a menos que ocorram fatos que coloquem em xeque seus valores intrínsecos (desafios de mercado, crises, súbito crescimento, troca do dirigente após uma longa permanência), ela tende a manter os mesmos valores iniciais. 
Freitas (1999, p. 87) recorda que "todo ser humano é um ser ao mesmo tempo singular e universal", que consiste, analogicamente, em um "arquivo próprio e particular" que embora existente desde seu nascimento, não disponibiliza conscientemente todos seus "dados e informações", mas que nos apresenta partes que somente podem ser compreendidas apenas de forma vaga e incompleta, a partir de certas pistas e reminiscências. Essa caracterização humana também pode ser aplicada ao contexto das organizações, de forma mais intensa quanto às questões inconscientes, na medida em que da mesma forma que os seres humanos, essas áreas "são ativas e podem ser resgatadas e atualizadas nossas relações cotidianas e ao longo de toda a nossa vida", estando presentes em todas as situações, "se apresenta e representa nas relações múltiplas do cotidiano".

A espiritualidade no ambiente de trabalho surgiu recentemente na literatura e no cotidiano das organizações, sendo entendida como o reconhecimento de que "as pessoas possuem uma vida interior, que alimenta e é alimentada por um trabalho com significado, realizado dentro do contexto de uma comunidade" (ROBBINS, 2005, p. 390). Apesar das críticas (em especial quanto à legitimidade de impor valores espirituais aos colaboradores e pelo potencial conflito com a lucratividade), é fato observável na realidade das organizações que as pessoas buscam sentido e propósito no trabalho que realizam e desejam atuar com outros indivíduos em comunidade, de forma mais completa, compreensível, já que o trabalho tornou-se o centro da vida da maioria das pessoas.

\section{Relações emocionais}

Para ilustrar esse tópico, foi escolhida a relação existente entre os seres humanos e seus filhos, que, parece-me a situação na qual as pessoas deitam por terra seus papeis formais: assim, da mesma forma que uns pais têm uma tendência natural a estimular o desenvolvimento racional (educacional e prático) de seus filhos mais aplicados e a proteger os mais problemáticos, e outros tendem a "descansar" do futuro dos primeiros ("afinal, ele já sabe o que quer e como obter") e a abandonar os segundos ao seu destino ("ele já fez a sua escolha"), também a instituição, em regra geral, tende a adotar posturas semelhantes. Analogicamente ao primeiro caso, a empresa oferece cursos de extensão ou equivalente aos funcionários mais "brilhantes" e adota posturas mais benevolentes com os menos destacados ("coitado, ele tem tantos problemas em casa, mas ainda assim se esforça, vamos lhe dar mais uma chance") e, comparativamente ao segundo, não investe nada nos funcionários que são eficientes ("em time que está ganhando não se mexe") e demite os que não atingem as metas propostas mesmo que por falta de investimento em treinamentos técnicos ("esse cara não tem interesse na empresa");

A comparação entre a disputa de poder nos altos escalões empresariais e o mito edipiano de conquista do lugar do pai é feita por Freitas (1999, p. 88), quando afirma que "as pessoas nas organizações disputam postos, poder, influência junto a outrem, querem ocupar lugares que pertencem a outros, numa atitude semelhante à da criança que quer o lugar do pai ou de alguém que lhe dificulte o acesso ao objeto amado e para tanto tem que "matá-lo",, assim como faz a analogia da competição entre pares pela disputa de poder para obtenção de reconhecimento e privilégios com a disputa entre irmãos pelo amor dos pais. Na mesma obra, a autora afirma: 
Fonte de aprovação ou reprovação, de prazer ou castigo, de aceitação ou rejeição, a organização pode configurar relações em que a atenção dos pais é substituída pela dos chefes, dos pares ou da organização enquanto um todo capaz de reconhecimento dos atributos do indivíduo singular, saído da massa e estrela brilhante, e do indivíduo como parte do conjunto, com direito a um assento no santuário partilhado. (FREITAS, 1999, p. 89)

FREITAS (1999, p. 87-94) aborda as relações entre o indivíduo e a organização, que ocorrem com as pessoas em seus diversos ambientes sociais:

- Transferência - conceituada como "um processo pelo qual os desejos e as emoções inconscientes se atualizam em certos objetos num tipo de relação vivida no passado", de acordo com a autora "é uma reedição de algo ocorrido antes e que pode se manifestar de diversas formas (do amor ao ódio, da simpatia à hostilidade) e em diferentes objetos". Assim, é possível comparar as atitudes institucionais tomadas sem fatos concretos que justifiquem claramente a relação causa $\mathrm{x}$ efeito, se assemelhando ao resgate de "motivações inconscientes que se baseiam em reminiscências de construções passadas".

- Identificação - "um processo psicológico pelo qual um sujeito assimila um aspecto, uma propriedade ou um atributo do outro e se transforma, total ou parcialmente, sob o modelo daquele". Esse conceito nos remete à constante realidade institucional em que a organização busca fazer com que seus colaboradores admirem suas chefias, utilizando-se, para isso, de métodos e técnicas que nos remetem ao papel aconselhador do pai, como o coaching, que tem sido uma ferramenta muito utilizada nas organizações nos últimos anos.

- Idealização - trata-se do "processo pelo qual as qualidades e o valor de um objeto são elevados à categoria de perfeitos [...] exerce uma atração irresistível ao prometer a partilha da perfeição e das delícias do Olimpo luminoso". Segundo a autora, esse tipo de relação nas organizações pode ser comparada à relação comum entre a criança e a mãe, na medida em que:

\footnotetext{
Merecer a honra de fazer parte do clube dos escolhidos, poder partilhar a missão nobre, respirar o aplauso, o amor e a aprovação da grande Mãe tem sua contrapartida na dependência infantil, pois a idealização de um objeto não favorece o amadurecimento nem a autonomia.. FREITAS (1999, p. 93)
}

Assim, verifica-se que as relações intra-organizacionais assemelham-se ao ambiente familiar básico, a família, repetindo seus rituais e

Dejours (2000) analisa a questão do papel desempenhado pelos gerentes, que são condicionados a realizar ações que se configuram em "injustiça social" interna para cumprir as metas organizacionais, que pode ser comparado ao papel alguns pais/mães estabelecem 
para os filhos "em nome da família" ou, ainda, às escolhas profissionais dos genitores para seus filhos, mesmo que incompatíveis com as aspirações destes.

\section{b) Modo De Agir}

Neste aspecto, compara-se a forma com que a organização interage com as demais instituições, equivalendo às relações sociais humanas, considerando, especialmente, as relações de poder, a busca dos afins e a capacidade de auto-organização.

Em todos os setores da vida cotidiana, estabelecemos vínculos que envolvem relações de poder com outras pessoas; assim, podemos comparar a empresa a uma pessoa no seu relacionamento com o ambiente externo, que, assim como o comparativo humano, podem ser agrupadas, de forma geral, em três categorias de atuação principal:

I. Cooperação - vínculos nos quais as relações de poder estão condicionadas à necessidade de parceria para atingir um objetivo convergente;

II. Competição - o poder é definido pela capacidade de uma parte atingir uma melhor posição em relação a um concorrente na busca de um objetivo comum, mas que permite apenas um vencedor final;

III. Dominação - é uma relação de dominação de uma parte pela outra, normalmente originada por algum tipo de dependência.

$\mathrm{Da}$ mesma forma que os seres humanos, as instituições estabelecem relações que muitas vezes, em momentos distintos, podem permear as três categorias apresentadas. As parcerias entre as empresas, nas quais as "menores" buscam aliar-se às de maior porte ou presença no mercado, como forma de minimizar a competição, podem ser comparadas, analogicamente, à forma de equilíbrio buscada na teoria da primatologia.

Na busca dos afins, como cita Davidoff (1983), os seres humanos selecionam as pessoas com as quais vão se associar, a partir de critérios internamente estabelecidos: as que apresentam as características desejadas (no geral, em nível médio, para que não sejam expostas nossas deficiências), aquelas nas quais percebemos sinceridade em sua atração por nós, as mais próximas fisicamente (pela facilidade de contato e que, no geral possuem forma de vida e preferências semelhantes), as que têm atitudes e valores semelhantes aos nossos e personalidades parecidas com as nossas e as personalidades complementares.

Para analisar as organizações, selecionou-se como exemplo os encontros de pescadores para falar do tamanho dos peixes (com a desculpa formal de discutir as melhores técnicas de pescar o salmão), os clubes de fumadores de charuto ou de provadores de vinho com o engodo de discutir os melhores produtos do mercado (quando, na realidade, buscam fazer parte de um grupo seleto do qual se sentem vaidosos de participar, "porque são pessoas como eu e entendem a minha língua"), assim como as empresas buscam encontrar-se com pessoas de seu ramo de atividade para seminários de "busca de soluções para o fator xyz" (quando, na realidade o que realmente desejam é estar com pessoas que "façam parte de seu mundo"). 
Capra (2007, p. 97) ao abordar o comportamento dos organismos vivos, resgata sua capacidade de auto-organização, ou seja, "o comportamento do organismo é determinado pela sua própria estrutura, estrutura essa que é formada por uma sucessão de mudanças estruturais autônomas".

\section{c) Modo de Pensar}

Para este tópico a escolha recaiu sobre a escolha da(s) área(s) de atuação da empresa ao longo do tempo, assim como suas opções estratégicas, que pressupostamente podem ser comparadas ao direcionamento da trajetória profissional e pessoal dos indivíduos.

\section{Escolha da área de atuação}

Seria temeridade afirmar se uma pessoa escolhe determinada carreira porque percebe que tem habilidades capazes de lhe garantir o sucesso nessa área ou se desenvolve as habilidades necessárias ao sucesso na carreira que escolheu, por isso consideramos que a escolha baseia-se na afinidade que ela tem com a área de opção. E, a partir dessa afinidade, naturalmente as habilidades encontram maior espaço de desenvolvimento, já que é fato que o que se faz com prazer provoca menor desgaste de energia. Mas mesmo a escolha baseada no prazer não lhe garantirá o sucesso, a menos que realmente possua perfil e vocação para a atividade, entendendo-se, para esse fim, perfil como o conjunto de características pessoais e técnicas compatíveis com o objetivo e vocação como um "dom" natural, capaz de fazê-lo buscar transpor os limites a cada instante.

Se observados os profissionais do mercado no exercício de suas atividades, verifica-se que a tendência de atuação das pessoas é, gradativamente, adotar a forma de pensamento comum à área em que atuam. Como exemplos ilustrativos, citamos o caso dos financistas, que, em qualquer tema que esteja sendo discutido, costuma perguntar, assim que possível, qual a relação custo x benefício que o assunto discutido oferece, mesmo que seja a escolha da nova televisão ou da substituição da empregada doméstica; os compradores; que insistem em fazer uma pesquisa de mercado, ainda que seja para descobrir a padaria onde ele comprará os dois pãezinhos diários; c) no caso de sociólogos ou cientistas sociais, a abordagem se foca nos elementos sociais que levaram a uma determinada situação. Substituindo-se essa pessoa pela instituição como foco da análise, podemos chegar à mesma conclusão, já que a tendência natural das instituições é avaliar as situações quase sempre apenas pelo foco da área na qual se insere, muitas vezes deixando aspectos muito mais relevantes relegados a um segundo plano.

As escolhas estratégicas, pessoais ou institucionais, estão condicionadas à autoimagem e à percepção de sua importância no ambiente. Capra $(2007$, p. 86) afirma que a capacidade de reter imagens mentais é condição fundamental para a existência da vida social, pois: "ela nos habilita a escolher entre diversas alternativas, o que é necessário para a formulação de valores e de regras sociais de comportamento". Por outro lado, o mesmo autor (CAPRA, 2007, p. 96) afirma que o significado de qualquer coisa somente ocorre a partir da relação que estabelecemos entre ela e outros elementos presentes, passados ou futuros. Segundo o autor, a capacidade de formar imagens mentais nos permite planejar e escolher entre alternativas, que conduzem à formulação de valores e regras sociais de comportamento, e, através da rede de comunicação humana, estabelece uma dinâmica coletiva, "que coordena 
continuamente o comportamento de seus membros" e da qual "nasce (...) o sistema integrado de valores, crenças e regras de conduta que associamos ao fenômeno da cultura"( CAPRA, 2007, p. 97).

\section{CONSIDERAÇÕES FINAIS}

A interação humana, componente fundamental das sociedades, adquire, no mundo contemporâneo, de estrutura capitalista, um novo enfoque, no qual as organizações assumem um valor substancialmente mais importante do que os indivíduos de forma isolada.

O termo "personalidade organizacional", quando ampliado para o contexto organizacional, foi o objeto desta pesquisa, de cunho exploratório, buscando identificar quais as características que poderiam ser comparadas entre pessoas e instituições, destacando-se Freitas, que afirma que "na tentativa de personificação das organizações, incorporam-se ao discurso vários atributos humanos, de modo que elas aparecem como perfeitas e capazes de restaurar a perfeição daqueles que elas elegeram como membros".

Os resultados indicam que diversos autores abordam o tema sob diferentes prismas, inexistindo uma visão única sobre como esse constructo se forma e desenvolve ao longo do tempo. No entanto, alguns pontos podem ser elencados preliminarmente como comuns, nas diferentes abordagens, comparativamente ao mesmo tempo no âmbito individual:

- a personalidade é constituída ao longo do tempo, com elementos de natureza intrínseca - características inatas - e condições ambientais - oportunidades externas que podem facilitar o desenvolvimento de determinadas habilidades;

- da mesma forma que o indivíduo, as organizações possuem crenças e valores que afetam seu "comportamento" e são afetadas pelo ambiente no qual está inserida; assim, por exemplo, a utilização desmesurada de estratégias mercadológicas está diretamente associada à existência de um mercado competitivo, condicionadas à importância atribuída à obtenção de benefícios - lucro, conquista de mercado, etc;

- as escolhas de natureza estratégica são decorrentes da imagem - interna e externa - que se pretende configurar ao longo do tempo;

- a forma de "pensar" das organizações está condicionada, em maior ou menor medida, de acordo com o ambiente de inserção, criando novos dogmas, replicados pelos membros na medida de seu fortalecimento ambiental;

- os mitos, assim como os heróis, são formas de manipulação do poder, na medida em que propiciam a sua utilização conforme o interesse específico - seja um genitor ou um gerente.

Embora não conclusivos, os resultados da pesquisa demonstram que as organizações podem ser comparadas aos seres humanos, no que se refere à construção e desenvolvimento da personalidade, embora com a necessidade de adequação em diversos aspectos. 
Considerando o peso da figura do "herói" na construção da personalidade individual e organizacional e suas implicações, estudos mais aprofundados estão sendo realizados.

\section{REFERÊNCIAS}

BIDERMAN, Maria Tereza Camargo. Dicionário didático de Português. São Paulo: Editora Ática, 1998.

BOEMER, Magali Roseira. A Condução de Estudos segundo a Metodologia de Investigação Fenomenológica. Rev. Latino-am. Enfermagem, Ribeirão Preto, v. 2, n. 1, p. 83-94. Janeiro 1994.

CAPRA, Fritjof. As Conexões Ocultas: Ciência para uma Vida Sustentável. São Paulo: Cultrix, 2007.

CARPENTER, C. R. Sexual behavior of free ranging rhesus monkeys (Macaca mulatta). II. Periodicity of estrus, homosexual, autoerotic and non-conformist behavior. Journal of Comparative Psychology, n. 33, p. 143-162. 1942

CHIAVENATTO, Idalberto. Recursos humanos. Edição compacta. São Paulo: Atlas, 1985

CROOK, J. H. Social organization and the environment: Aspects of contemporary social ethology. Animal Behavior,, n. 18, p. 197-209. 1970.

DAVIDOFF, Linda D. Introdução à Psicologia. São Paulo: McGraw-Hill do Brasil, 1983.

DEJOURS, Christophe. Banalização da Injustiça Social. Luís Alberto Monjardim (trad). Rio de Janeiro: Editora Fundação Getúlio Vargas, 2000.

DIGMAN, J. M. (1996). The curious history of the five factor model. In J. Wiggens (ed.), The Five Factor Model of Personality (pp. 1-20). New York: Guilford. 1996.

ENRIQUEZ, Eugène. L'Organisation en analyse. Paris: P.U.F. 1992.

A organização em análise. Petrópolis: Vozes, 1997. 
FOSSÁ, Maria Ivete Trevisan. O Simbólico e o Imaginário na Organização. Rio Grande do Sul, 2004. Anais... IV Encontro dos Núcleos de Pesquisa Intercom - Sociedade Brasileira de Estudos Interdisciplinares de Comunicação. 30 de agosto a 3 de setembro de 2004, Pontifícia Universidade Católica - PUC - do Rio Grande do Sul, Porto Alegre. Disponível em:<http://www.portcom.intercom.org.br/pdfs/9634663981307156385409108649554958449 2.pdf $>$. Acesso em: 20 set. 2014.

FREITAS, Maria Ester de. Cultura organizacional: identidade, sedução e carisma?. Rio de Janeiro: Editora FGV, 1999.

Cultura organizacional: Identidade, sedução e carisma? Rio de Janeiro: Editora FGV, 2002, $3^{\text {a }}$. Ed.

KUMMER, H. Social organization of hamadryas baboons. Chicago: University of Chicago Press. 1968.

LEVI-STRAUSS, C. O pensamento selvagem. $8^{\text {a }}$ ed. Campinas, São Paulo: Papirus, 1989.

LORENZ, K. Evolution and modification of behavior. Chicago: University of Chicago Press. 1965.

ROBBINS, Stephen Paul. Comportamento Organizacional. $9^{a}$ ed. São Paulo: Prentice Hall, 2008.

ROBBINS, Sthephen P. Comportamento organizacional. $11^{\text {a }}$ ed. São Paulo: Pearson Prentice Hall, 2005.

RUBEN, R. G. La cultura organizacional. Un potencial activo estratégico desde la perspectiva de la administración. Invenio, v.12, n.22, p.67-92, jun., 2009.

TRENTINI, C. M.; HUTZ, C. S.; BANDEIRA, D. R.; TEIXEIRA, M. A. P.; GONÇALVEZ, M. T. A.; THOMAZONI, A. R. Correlações entre a EFN - Escala Fatorial de Neuroticismo e o IFP -Inventário Fatorial de Personalidade. Avaliação Psicológica, v. 8, n. 2, p. 209-217. 2009.

TRICE, H.M.; BEYER, J.M. Studying organizational cultures through rites and ceremonial. Academy of Management Review, v. 9, n. 4, p. 653-699, 1984 
VERÍSSIMO, Manuela; SANTOS, António J.. Desenvolvimento social: Algumas considerações teóricas. Aná. Psicológica, Lisboa, v. 26, n. 3, jul. 2008 . Disponível em: $<$ http://www.scielo.gpeari.mctes.pt/scielo.php?script=sci_arttext\&pid=S0870$82312008000300002 \& \operatorname{lng}=$ pt\&nrm=iso $>$. Acesso em: 20 set. 2014.

YERKES, R. M. The great apes. New Haven, Connecticut: Yale University Press. 1928.

ZUCKERMAN, S. The social life of monkeys and apes. London: Rutledge \& Kegan Paul. 1932. 